\title{
Study on the Ban on Free Plastic Bags in China
}

\author{
Xiufeng Xing \\ School of economy and trade \\ Qingdao Technological University \\ Qingdao 266520, China \\ E-mail: xxfqd@126.com
}

The research is financed by Shandong Social Science Planning Programme.No.08JDD013

\begin{abstract}
On Jun $1^{\text {st }}, 2008$, the production, sale and use of plastic shopping bags 0.025 millimeters thick or thinner will be banned in China under a State Council decree, and retailers will be prohibited from providing customers with free plastic bags, which is called by the general public the ban on free plastic bags (or plastic limit order). Since the implementation of the policy, the use of plastic bags has decreased dramatically, meanwhile, the public awareness of environmental protection has also been enhanced. Nevertheless, there still leaves much to be desired, for instance, some plastic bags provided to the consumers do not meet the national standards, and auxiliary bag without carrying function has been double-charged. According to Polluter pays principle, coupling with the means of product charge, the paper analyzes the impact of the ban, evaluates on its results and then puts forward some relevant measures on the above basis.
\end{abstract}

Keywords: Ban on free plastic bags, Polluter pays principle, Corporate social responsibility, Resources-saving and Environmental-friendly society

\section{Analysis on the ban on free plastic bags in China}

Chinese ban on plastic bags consists of two regulations: the compulsory national standard of plastic bags and the management of compensation for the use of plastic shopping bags in retail establishments. The former stipulates that the plastic bag should be no less than 0.025 millimeters thick, while the latter requires that the selling price of the plastic bags be higher than operating costs. In addition, on Jul $10^{\text {th }}, 2008$, Chinese Ministry of Commerce, National Committee of Development and Reform, and State Association of Industry and commerce made a joint supplementary provision which expand the scope of application, according to which restaurants and bookstores are included.

\subsection{Analysis on the relationship between product charge and use of plastic bags on the basis of polluter pays principle}

The Polluter Pays Principle (PPP) is a principle where the polluting party pays for the damage done to the natural environment. The basic tenet of PPP is that the price of a good or service should fully reflect its total cost of pollution control. The PPP is the chief economic principle for environmental policy including product charges. With respect to product charges, this generally refers to the charge for a product that generates emission or discharge in the course of production and consumption to raise the price level. The purpose is to reduce product use and manufacture less pollution product and raise the capital for pollution prevention or treatment. Tax difference is a special case of product charges which means to make additional positive or negative charges on the product levied according to its different environmental impact.

In theory, through the use of price signals and tax difference in accordance with PPP, it is conductive to change people's plastic bags dependence gradually, form the habit of reuse plastic bags, and thus reduce the discharge and harness cost of "white pollution".

\subsection{Brief analysis on the enforcement and its policy effects on the ban on plastic bags}

If carried out effectively, the ban will make a fundamental impact on all aspects of China economy and society: from the perspective of micro level it will change the public awareness of environmental protection; from the perspective of middle-level, it will change dramatically to the production industry of plastic bags; from the perspective of macro level, namely from the perspective of the whole society in China, it will definitely help the construction of resources-saving and environmental-friendly (or eco-friendly)society and sustainable development. In other words, it can improve the ecology system and save a lot of expenditure on pollution control, in the meantime, the public awareness of environmental protection and corporate social responsibility will be enhanced, which are the main intention of the 
policy. The subject on corporate social responsibility has been studied previously. (Carroll, 2007, pp.122-131).

\section{Evaluation on the results of the ban on free plastic bags}

\subsection{Evaluation of the results on the ban on free plastic bags}

Stage results obtained are as follows. (1) Wang (2008,p.3) reported that the ban worked well in circulation in shopping malls and supermarkets, and the total use of plastic bags had reduced two-thirds roughly by Jul $12^{\text {th }}$. (2) Public awareness of environmental protection has been somewhat improved than before, customers or consumers come to accept the charge on plastic bags and bring their own carrying bags with them when shopping.

\subsection{Problems existing}

The outstanding problems include: (1) Markets is the most difficult place to carry out the policy. Traders often have 2 kinds of plastic bag, one of which meets the national standard and is only used to cope with the inspection, while the other is thinner than 0.025 millimeters which should have been prohibited from providing to consumers. Compared with the supermarkets which offer standard plastic bags, it is the markets that provide consumers free Ultra-thin plastic bags that become the body of the "white pollution". (2) Plastic bags provided by a small number of commercial enterprises are far from the national standard. Though Chinese Ministry of Commerce, National Committee of Development and Reform, and State Association of Industry and commerce made a joint supplementary provision on Jul $10^{\text {th }}, 2008$, which stipulated that from October of 2008, plastic bags without specific Logo should be terminated. At present, some business enterprises still use the sub-standard auxiliary bag (or pre-packaging roll bag), for example, the bags have no such Logo as "for food use", "QS", enterprise information, and the thickness is thinner than the required standard. Besides, there exists problem like repeated charges (or double-charged) on the consumers on standard bag, the higher the price of the goods, the more charges paid shifted to the business. The expensive fresh good is a good case in point, for the weight of bags hasn't been subtracted from the total weight. Obviously, the purchase cost of the bags has been shifted to the customers covertly and the retailers make money from the deal accordingly. (3)There is lack of effective substitute for plastic bag. Non-woven cloth bag is now accepted widely. Actually non-woven cloth is plastic which is not biodegradable and will result in huge consumption on non-renewable resources such as oil. It can be used as transitional goods but should avoid excessive use so to prevent it from being another source of white pollution after plastic bag. (4) The ban wants for supporting measures. The single-fee system can't guarantee the effective fulfillment of the goal; both consumer and shop are bound to pay for the environment. To all-round implement the ban on free plastic bags, supporting measures on controlling plastic pollution should be released accordingly.

\section{Policy suggestions on the perfection of the ban on free plastic bags in China}

The purpose of the release of the ban on free plastic bags is to improve the awareness of the public on environmental protection, eliminate white pollution, and build up the resources-saving and eco-friendly society gradually. To fulfill the aim, several measures including restriction, substitution and reclamation must be taken.

\subsection{Implement the form of deposit or refund to encourage or restrain the production and use of plastic products}

As mentioned above, one role of product charge is to reduce the product use and the other is to raise the fund. Actually tax difference can be views as a special case of the former, whose purpose is to generate stimulation function by positive or negative charge to raise or cut the price level. Given the real situation of the ban, the paper suggests that tax difference be carried out at an appropriate time to intensify the policy impact. The deposit-refund system originally means when the potentially pollutant product is sold, a deposit should be charged simultaneously, and the deposit will be refunded only after the buyer return the residues to the designated collecting system so to avoid pollution. Presently China only recollects solid residues such as beer bottle, but to the author's viewpoint, the deposit-refund system can also be extended to the recyclable plastic bags. By doing so we can improve the environmental protection awareness of the public step by step without increase the burden on consumer, while the social cost of the system is shared by government, production and commercial enterprises to shoulder the social responsibility. For the purpose of harness the white pollution and the realization of the resources-saving and eco-friendly society, Chinese governments should take appropriate way to subsidize those manufactures which meet the environmental protection standard in production and research link and those reclaim waste plastic enterprises. Meanwhile, repeated charges (double-charged) on the consumers should be rectified seriously.

\subsection{Develop the qualified substitutes as soon as possible}

Qualified substitutes must be developed as quickly as possible, as to plastic bags which don't meet certain standard, particularly the auxiliary bag, supervisions and punishment must be strengthened until the product is standardized. Fu (2008,p.13)has reported that the qualified substitutes include biodegradable plastic bag, qualified cotton bag with carrying function and paper bag made of recyclable paper. At present, paying for the plastic bag by general public is the only way to practice the ban on free plastic bag, while other measures such as using the tax preferential policy to manufacture biodegradable plastic bag and qualified cotton bag haven't been introduced. Some experts point out that 
only a small portion of plastic bags can be partially biodegradable under certain condition. The totally biodegradable plastic bag is less competitive than the non-biodegradable or partially biodegradable ones for its high-tech, high production cost and small scale. In this case, government should issue relevant policy to encourage and stimulate the research and produce of the totally biodegradable plastic bag.

\subsection{Strengthen the life cycle assessment of plastic bags}

Life cycle assessment is the assessment of the environmental impact of a product in a cradle-to-grave approach. It is also known as life cycle analysis. Through life cycle assessment a comparison can be made of the environmental performance of products and services in order to choose the least harmful one. The theory of life cycle assessment has been studied previously. (Theo de Bruijn, 2007, pp.312-313).According to this theory, through the life cycle analysis all the pollution from the stage of production, use, reclamation of plastic bags should all be taken into account. It is impossible to eliminate plastic bag in China for the time being, what can be done is to change people's attitude towards plastic bag progressively through market-oriented approach to reduce the use, say make recharge or refund to those carrying his own bag when shopping. As for the reclamation, it is the producers and retailers that are responsible for the whole cycle of the product; this is also the key of the polluter pays principle. It is crucial to build up the complete environmental management system.

\subsection{Make efforts on environmental education for general public in China}

The environmental education in China starts late and the public are not actively participated as those in developed countries. According to a survey conducted in 2007 by China Environmental Culture Promotion Association to 9011 residents aged from 18 to 65 cross 31 provinces nationwide, although environmental pollution ranked second among the nine most concerned questions, $66.9 \%$ of people argue that China confront serious environmental problems, only $13.7 \%$ think they play an important role in the process of environmental protection, nearly half people don't think they are of great importance. The survey shows that awareness on environmental protection is lacking for Chinese people and the responsibility on environmental protection rely much on government. Though the ban on plastic bag has been put into practice for several months, some consumers still lack the consensus on the relationship between the meaning of the ban on free plastic bag and environmental protection and the use of the charge. After carrying out their social responsibility respectively, government and relevant enterprises should seize the opportunity to make propaganda for environmental protection, improve the public's awareness, and narrow the environmental education gap between history and present so to speed up the construction of resources-saving and eco-friendly society.

\section{References}

Fu, Zimei. (2008). Only With Various Measures Can the Aim of Ban on Free Plastic Bag Be Fulfilled. People's Daily. 16 June 2008.

Wayne, Visser, \& Dirk, Matten (2007). The A to Z of Corporate Social Responsibility. In Carroll, Archie, Corporate Social Responsibility. England: John Willey \& Sons, Ltd. pp.122-131.

Wayne, Visser, \& Dirk, Matten (2007). The A to Z of Corporate Social Responsibility. In Theo de Bruijn, Life Cycle Assessment. England: John Willey \& Sons, Ltd. pp.312-313.

Wang, Mingfeng. (2008). One Month after the Implementation of the Ban on Free Plastic Bag: "How Much Does the White Pollution Reduce?" People's Daily Overseas Edition. 12 July 2008. 